Article

\title{
Methods for Sampling Biogas and Biomethane on Adsorbent Tubes after Collection in Gas Bags
}

\author{
Karine Arrhenius *(D), Andreas Fischer and Oliver Büker \\ RISE Research Institutes of Sweden, 50115 Borås, Sweden; andreas.fischer@ri.se (A.F.); oliver.buker@ri.se (O.B.) \\ * Correspondence: Karine.arrhenius@ri.se; Tel.: +46-70-567-5728
}

Received: 27 February 2019; Accepted: 14 March 2019; Published: 20 March 2019

check for updates

\begin{abstract}
Biogas is a renewable energy source with many different production pathways and numerous excellent opportunities for use; for example, as vehicle fuel after upgrading (biomethane). Reliable analytical methodologies for assessing the quality of the gas are critical for ensuring that the gas can be used technically and safely. An essential part of any procedure aimed at determining the quality is the sampling and transfer to the laboratory. Sampling bags and sorbent tubes are widely used for collecting biogas. In this study, we have combined these two methods, i.e., sampling in a gas bag before subsequent sampling onto tubes in order to demonstrate that this alternative can help eliminate the disadvantages associated with the two methods whilst combining their advantages; with expected longer storage stability as well as easier sampling and transport. The results of the study show that two parameters need to be taken into account when transferring gas from a bag on to an adsorbent; the water content of the gas and the flow rate used during transfer of the gas on to the adsorbent.
\end{abstract}

Keywords: biogas; biomethane; sampling; bags; flow rate

\section{Introduction}

Biogas can be produced from different substrates (inclusive food wastes, sludge from water treatment plants, manure, etc.) and consists mainly of methane and carbon dioxide. However, biogas also contains many other gaseous substances called VOCs (volatile organic compounds) [1,2], but in much lower concentrations. Some of these substances have undesirable odours and may damage the process and/or the equipment and can be harmful for the environment and/or human health. It has been shown that the contaminants that form in the biogas depend on the substrate and the control parameters [3]. Terpenes and, specifically, p-cymene and D-limonene have repeatedly been in biogas samples originating from plants where household waste is digested. Alkanes (linear and aromatic) and siloxanes occur in significant quantities in biogas from wastewater treatment plants. Ketones and sulphur compounds are usually found in biogas produced by the digestion of energy crops and by-products from industry.

Biogas has many applications; especially applications already using natural gas. Worldwide, biogas is currently used primarily for electricity production; however, biogas is also widely used after upgrading to biomethane as vehicle fuel. If biogas is to be injected into the natural gas grid or used directly as a vehicle fuel, carbon dioxide must be removed so the methane fraction is typically increased to above $96 \%$. Depending on the upgrade method (water scrubber, amine scrubber, pressure swing adsorption, membranes, etc.), some of the contaminants present in the biogas may still be present in the upgraded gas.

For other applications, biogas shall also be upgraded because some of the compounds found in the biogas are harmful to the infrastructure. Therefore, depending on the application, several specifications related to biogas and biomethane have been adopted. It is then important to control the 
quality of the product (biogas or biomethane) against these specifications to insure the integrity of the end-user's appliances $[4,5]$.

But before this assessment can be made, biogas and/or biomethane need to be sampled and transported to the laboratory. During this step, which can take from some days to up to a week, the composition of the gas collected shall not be altered [6]. This requires accurate and representative sampling. One risk is the loss of impurities by absorption onto the inner surfaces of the sampling vessel. It is therefore necessary to choose the sampling vessel after having fully assessed the short-term stability of the impurities of interest in the vessels.

However, the impurities of interest have different properties (with regards to their boiling points, polarities, water solubilities and reactivities). Recently, a literature survey [7] pointed out that it may be impossible to find a vessel that will be suitable for all impurities and thus, combining several vessels will probably be required.

There are two main methods of sampling. Sampling without enrichment is mostly performed in cylinders, canisters or bags. Sampling with enrichment is mostly performed by adsorption onto adsorbent tubes or by adsorption in a solution using impingers.

The sampling of biogas in bags has been widely investigated. Most of the studies have used Tedlar bags for this application [8-13]. Other bags have also been tested in some studies (Nalophan [14], Teflon [15] or so-called Plastigas [16]). Sampling bags present the advantage to be easy to use; the sampling is simple and fast, do not require skilled personnel or a lot of additional equipment. For instance, no coolants or flowmeters are required. The disadvantages are that the method does not allow enrichment while, with some analytical instruments, the detection limit requires a larger volume of gas to be sampled. Moreover, studies $[6,10,17]$ have shown that a reduction in the concentration may occur when the gas is stored in a bag for a few days. The loss in concentration seems to occur to a greater extent during the initial storage period, during which the inner surfaces become saturated. The loss of concentration appears also to be related to the boiling point of the compounds [7]. Finally, transporting gas bags containing biogas and biomethane is also a challenge because they have to be treated as dangerous goods due to their flammability, which requires the consignments to be accompanied by transport documents complying with the regulations in place.

Sorbents have also widely been used to collect biogas and biomethane $[10,13,14,18-21]$. The advantage is that only the compound(s) of interest are adsorbed while the matrix passes through. In this way, it creates an enrichment of the targeted compounds. Another advantage when using sorbent tubes is that they are easy to transport to the laboratory (small sizes, no gas to transport). The reliability of sorbents for many of the compounds, such as Tenax TA [7], has been assessed for biogas/biomethane and good storage stability (up to a week) has been demonstrated. The disadvantage is that it requires a known volume of gas to be collected at an adequate flow using additional equipment, such as flowmeters, which can only be performed by trained personnel. The optimum flow rate used to collect VOC samples on $\frac{1}{4}$-inch $(6.35 \mathrm{~mm}$ ) O.D. tubes is $50 \mathrm{~mL} / \mathrm{min}$ [22] (for air, no value has yet been published for biogas or biomethane) and flow rates from 10 to $200 \mathrm{~mL} / \mathrm{min}$ are typical. Higher sampling flow rates in excess of $200 \mathrm{~mL} / \mathrm{min}$ are not recommended, unless for short term monitoring (e.g., $10 \mathrm{~min}$ ). However, high sampling flow rates have been used for high boiling point materials, such as PCBs (polychlorobiphenyls) and PAHs (polycyclic aromatic hydrocarbons) [23].

In this study, we have combined the two methods, i.e., sampling in a gas bag before subsequent sampling on to tubes in order to demonstrate that this alternative can help remove the disadvantages associated with the two methods, while combining their advantages; with expected longer storage stability as well as easier sampling and transport. For this purpose, we have evaluated and compared three methods to sample real biogas and biomethane samples from a bag on to Tenax tubes; using a gas syringe, an easy-VOC grab sampler and a sampling pump combined with a flowmeter. The two first methods can be used directly onsite, as they do not require any electrical power. 


\section{Materials and Methods}

\subsection{Analysis Method}

The Tenax tubes were desorbed using a Markes TD100 thermal desorber with two-stage desorption; the compounds are first released under heat $\left(275^{\circ} \mathrm{C}\right.$ for $\left.7 \mathrm{~min}\right)$ to a cold trap which is in the second stage quickly heated so the VOCs are released and reach the gas chromatographic column where they are separated. The instrument used for the analyses is an Agilent technologies $6890 \mathrm{~N}$ coupled with a flame ionization detector and a 5975C inert MSD mass spectrometer (in electron impact, EI, mode). The GC column is a BPX5 nonpolar capillary column (5\% phenyl polysilphenylene-siloxane, $50 \mathrm{~m}$ long, $0.32 \mathrm{~mm}$ internal diameter, $1 \mu \mathrm{m}$ film thickness). The initial GC oven temperature was $35{ }^{\circ} \mathrm{C}$ (hold $4 \mathrm{~min}$ ). The oven temperature was then raised with three ramp rates: to $100{ }^{\circ} \mathrm{C}$ at $3{ }^{\circ} \mathrm{C} / \mathrm{min}$, to $220^{\circ} \mathrm{C}$ at $8{ }^{\circ} \mathrm{C} / \mathrm{min}$ and, finally, to $300{ }^{\circ} \mathrm{C}$ at $15^{\circ} \mathrm{C} / \mathrm{min}$. The temperature was then held at $300^{\circ} \mathrm{C}$ for $10 \mathrm{~min}$. For detection, one part of the effluent is sent to a flame ionization detector and the other part to the mass spectrometer. VOCs are then quantified using the relative response factors to toluene and external curve (response ratio versus amount ratio) for toluene, with the FID signal. For most of the compounds, their relative response factors to toluene have been determined experimentally during other projects [6] by plotting responses ratio (compound/toluene) against amounts ratio (compound/toluene). For the remaining compounds, their relative response factors to toluene have been determined theoretically using the concept of the effect carbon number [24]. The mass spectrometer is used for identification by comparing the mass spectrum of each compound to mass spectra gathered in a database (NIST05a).

\subsection{Sampling Method}

\subsubsection{Method 1}

The setup for method 1 is presented on Figure 1. One-hundred millilitres of gas is drawn from the bag (ALTEF gas bag with polypropylene fitting ( $3 \mathrm{~L}$ ) (Restek)) on to the Tenax TA using a glass, gas-tight $100 \mathrm{~mL}$ syringe (SGE Analytical Science, Trajan Scientific and Medical, Australia). The flow across the Tenax TA tubes is from 150 to $200 \mathrm{~mL} / \mathrm{min}$.

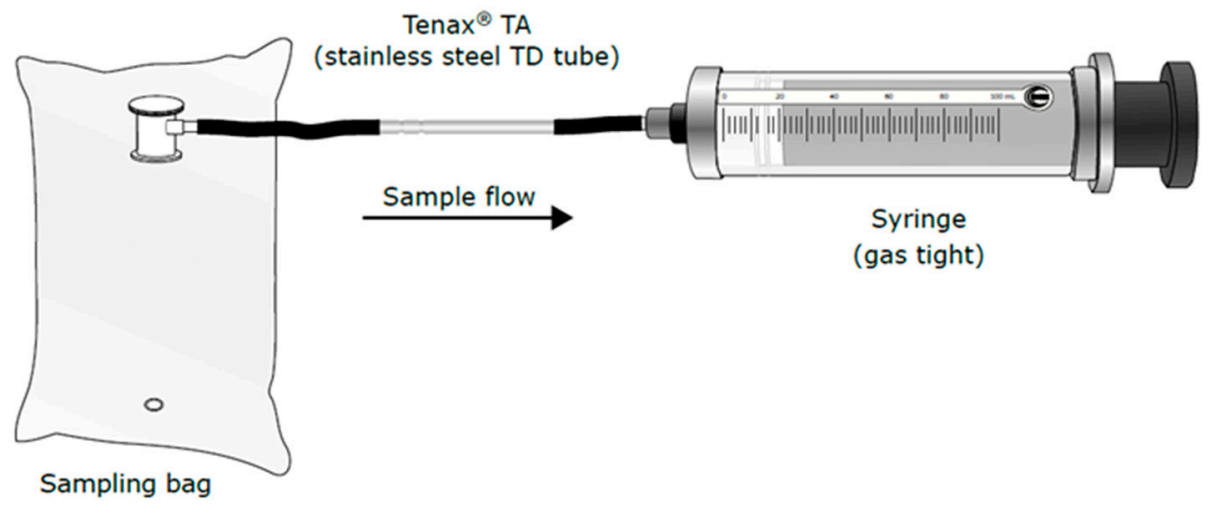

Figure 1. Sampling method 1—syringe method.

\subsubsection{Method 2}

The setup for method 2 is presented on Figure 2. One-hundred millilitres of gas is drawn from the bag (ALTEF gas bag with polypropylene fitting (3 L) (Restek)) on to the Tenax TA using an easy-VOC grab-sampler (Markes International Ltd., Llantrisant, UK). According to the manufacturer, and in contrast to method 1, easy-VOC regulates the flow rate across the Tenax TA tubes independently of the force used to pull the gas through by using an internal restrictor to ensure that a consistent flow is maintained throughout the sampling process. Typical flow rates are $~ 500-600 \mathrm{~mL} / \mathrm{min}$. 


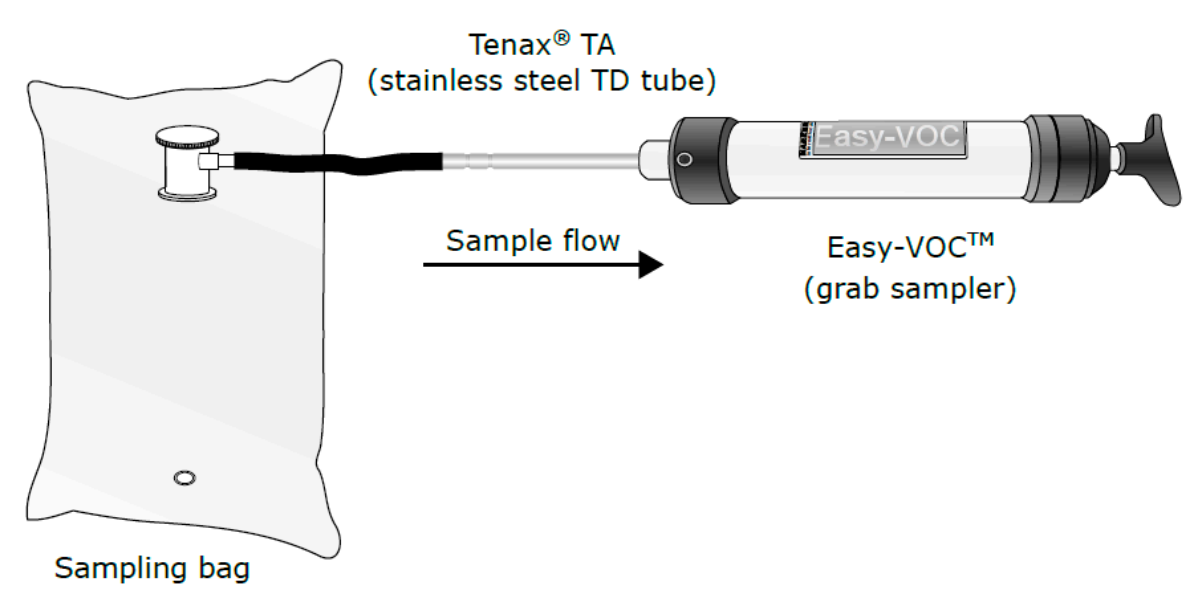

Figure 2. Sampling method 2-Easy volatile organic compound (VOC) method.

\subsubsection{Method 3}

The setup for method 3 is presented on Figure 3. One-hundred millilitres of gas is drawn from the bag (ALTEF gas bag with polypropylene fitting (3 L) (Restek, Bellefonte, PA, USA)) on to the Tenax TA using a universal sampling pump (SKC Ltd., Blandford Forum, UK). The flow rate across the tube is regulated to $50 \mathrm{~mL} / \mathrm{min}$ using a laminar flowmeter from Alicat, which is calibrated for the composition of the gas to be sampled.

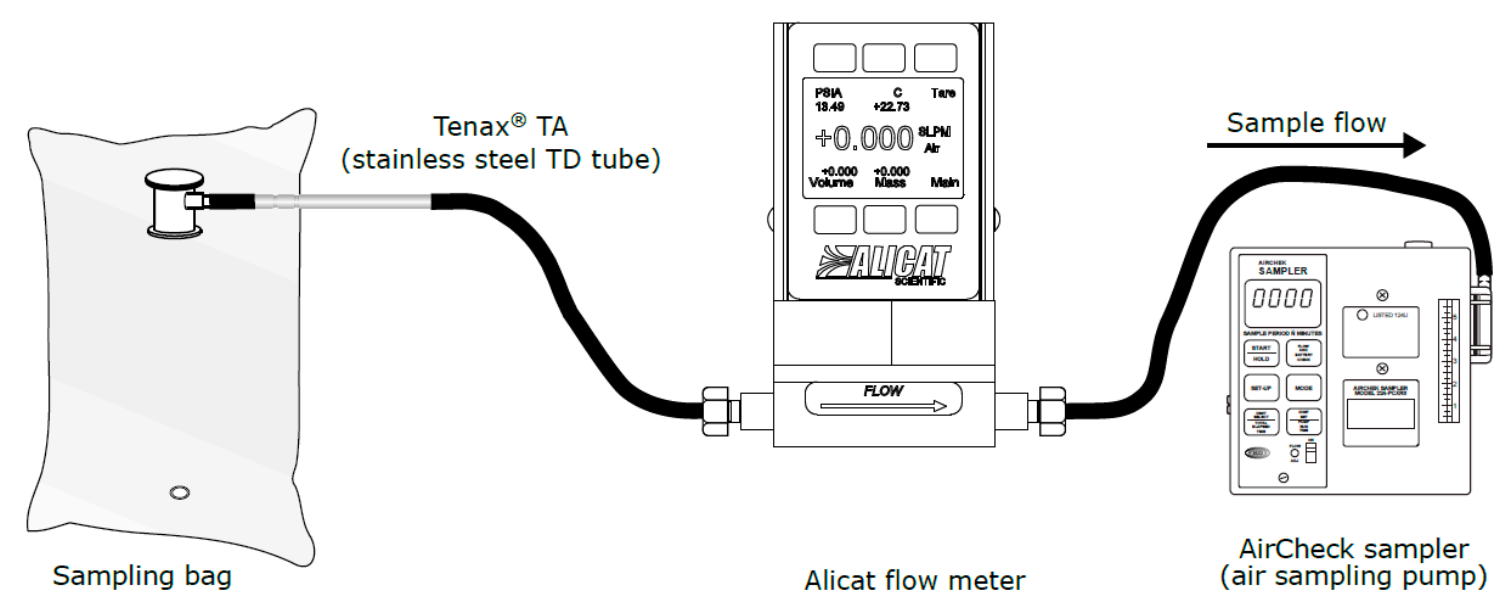

Figure 3. Sampling method 3-Sampling pump method.

\section{Biogas and Biomethane Samples}

In total, 14 samples of biogas and six samples of biomethane were collected in Altef gas bags. The samples were real samples collected from different biogas plants and covering different substrates including waste water treatment sludge, food wastes and industry wastes. The biomethane used in this study samples originated from biogas upgraded either using a water scrubber or an amine scrubber. From the bags, $100 \mathrm{~mL}$ of gas was drawn on to Tenax TA tubes using each of the three methods (three tubes per method) at the same time (within a $30 \mathrm{~min}$ period). The total storage time was in all cases less than 1 day. Between 5 to 15 VOCs were quantified for each sample; 130 VOCs in total. The VOC concentrations varied from $30 \mu \mathrm{g} / \mathrm{m}^{3}$ to $35,000 \mu \mathrm{g} / \mathrm{m}^{3}$ as shown on Figure 4 . The VOCs belong to several different families: linear alkanes (heptane, octane, decane, undecane, dodecane, tridecane and tetradecane), aromatic hydrocarbons (toluene and o-xylene), terpenes ( $\alpha$-pinene, $\beta$-pinene, camphene, 3-carene, D-limonene and p-cymene), sulphur compounds (dimethyl sulphide, dimethyl disulphide, thiophene, 2-methylthiophene, tetrahydrothiophene and 1-propanethiol), alcohols (1-propanol and 2-butanol), ketones (2-butanone, 3-pentanone and 2-pentanone), esters 
(ethyl propanoate, ethyl butanoate and ethyl pentanoate), furans (2-methylfuran and ethyl-furan) and other alkanes (decahydronaphthalene and methyldecahydronaphthalene). Boiling points vary from $38^{\circ} \mathrm{C}$ (dimethyl sulphide) and $234^{\circ} \mathrm{C}$ (tetradecane).

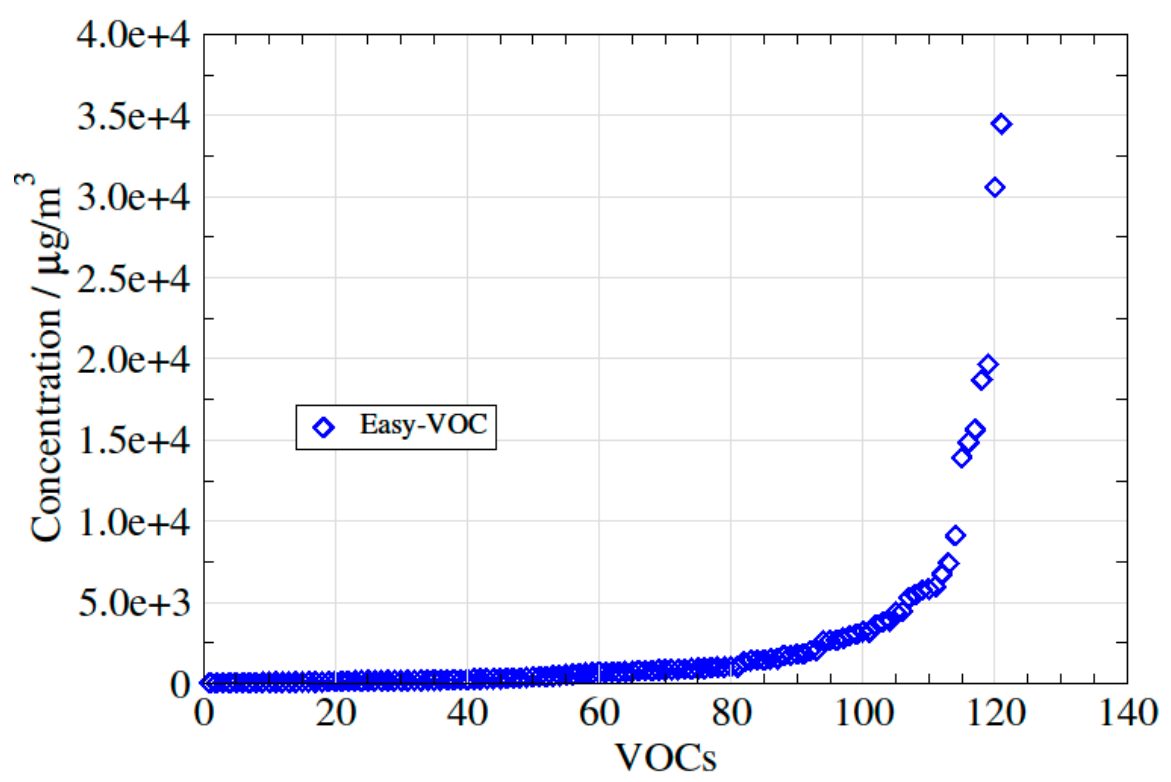

Figure 4. Variation in concentration for the 130 VOCs measured in this study.

\section{Results and Discussions}

\section{Standard Deviation}

For one sample, ten tubes were taken using each of the tested methods. The precision of the results of the experiment is shown in Table 1 for eight different VOCs. The relative standard deviations of the measured VOC concentrations for most of the tests are lower than $5 \%$ rel., with the exception of methyl propyl disulphide using the EasyVOC method (6.2\%) with undecane, $\alpha$-pinene and $\beta$-pinene $(6.4 \%, 5.7 \%$ and $5.6 \%$, respectively) using the sampling pump method (at a flow rate of $50 \mathrm{~mL} / \mathrm{min}$ ).

Table 1. Relative standard deviation $(n=10)$ of the 3 methods and VOCs.

\begin{tabular}{|c|c|c|c|c|c|}
\hline \multirow{2}{*}{$\begin{array}{c}\text { Rel. Standard Deviation } \% \\
\text { Flow rate }(\mathrm{mL} / \mathrm{min})\end{array}$} & \multirow{2}{*}{$\frac{\text { EasyVOC }}{500}$} & \multicolumn{2}{|c|}{ Syringe } & \multicolumn{2}{|c|}{ Sampling Pump } \\
\hline & & 150 & 300 & 50 & 150 \\
\hline Dimethyl sulphide & 1.3 & 1.1 & 1.6 & 3.8 & 1.9 \\
\hline Dimethyl disulphide & 1.5 & 0.7 & 0.8 & 2.9 & 2.5 \\
\hline Methyl propyl disulphide & 6.2 & 1.4 & 2.1 & 4.6 & 2.4 \\
\hline 2-methylfuran & 0.9 & 3.4 & 4.1 & 3.6 & 1.3 \\
\hline Undecane & 3.4 & 0.3 & 2.8 & 6.4 & 3.1 \\
\hline Toluene & 1.6 & 0.8 & 1.7 & 4.3 & 2.3 \\
\hline$\alpha$-pinene & 4.1 & 2.0 & 1.5 & 5.7 & 2.6 \\
\hline$\beta$-pinene & 5.0 & 1.8 & 1.7 & 5.6 & 2.6 \\
\hline 3-carene & 2.5 & 0.9 & 1.7 & 4.2 & 2.8 \\
\hline p-cymene & 1.9 & 3.1 & 2.2 & 4.9 & 3.2 \\
\hline
\end{tabular}

The concentrations measured for 10 VOCs using the three methods (including two different flow rates for the sampling pump method) are shown in Figure 5a. The agreement between the methods is clearly satisfactory, with the exception of the sampling pump method at a flow rate of 50 $\mathrm{mL} / \mathrm{min}$ for $\alpha$-pinene, $\beta$-pinene, 3 -carene and p-cymene. These compounds have higher boiling points than the other compounds compared in this test. The chromatogram for method 1 is presented in Figure $5 \mathrm{~b}$. The current study focuses on real samples of biogas and biomethane. In a previous study [6] 
about the storage stability of impurities as siloxanes, sulphur compounds, halogenated and aromatic hydrocarbons, gravimetrically-prepared reference gas standards were stored in the same type of bags. The results were obtained using method 1 and show that satisfactory recovery yields ( $>90 \%)$ were obtained (storage duration < one day).

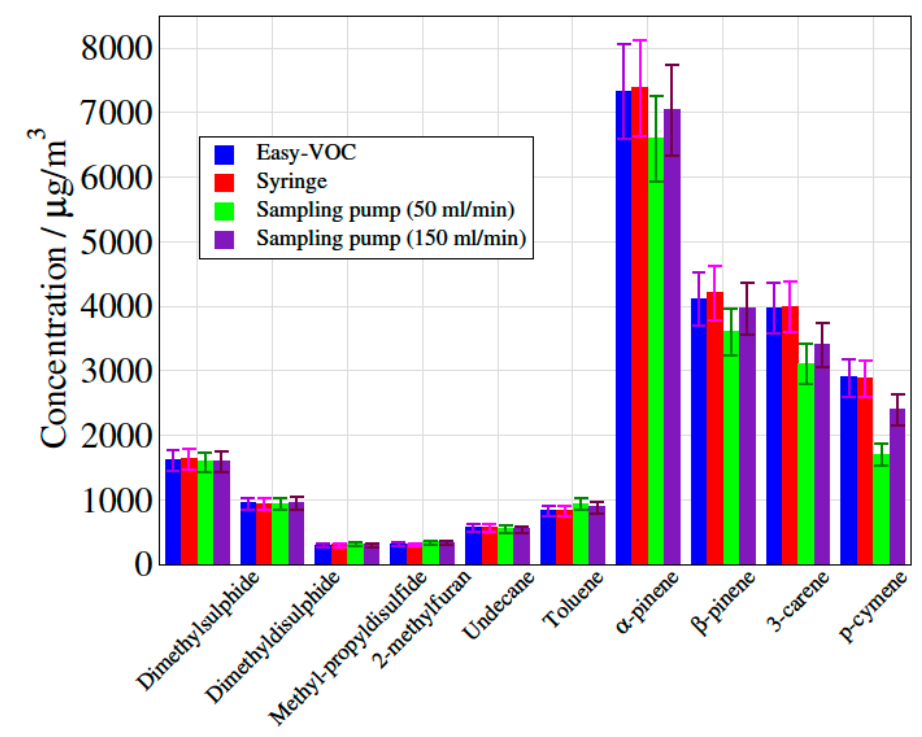

(a)

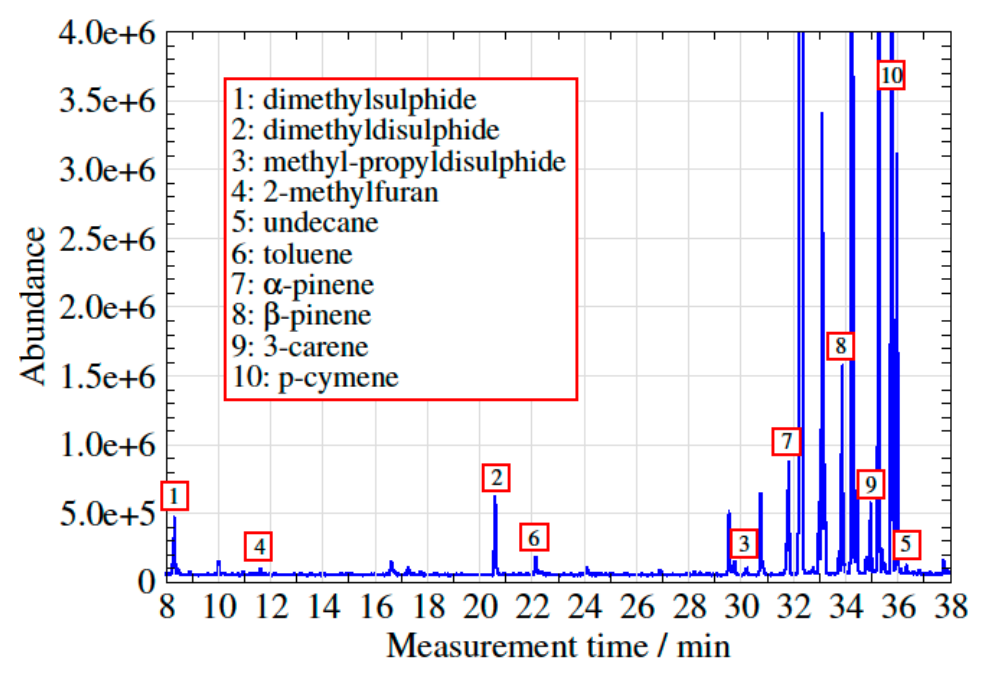

(b)

Figure 5. (a) Comparison of concentrations measured using the 3 different methods. (b) Chromatogram obtained with method 1.

In order to verify this preliminary observation, 14 different samples of biogas/biomethane (in total 130 VOCs) were analysed using the three different methods, using a flow rate of $200 \mathrm{~mL} / \mathrm{min}$ for the syringe method, $500-600 \mathrm{~mL} / \mathrm{min}$ for the EasyVOC method and $50 \mathrm{~mL} / \mathrm{min}$ for the sampling pump method. The results were plotted in three different figures (Figures 6-8), using the EasyVOC method as the reference for both comparisons (Figure 6: comparison between syringe method and EasyVOC method; Figure 7: comparison between sampling pump method and EasyVOC method for samples with low water vapour content $<0.8$ vol-\%; Figure 8 : comparison between sampling pump method and EasyVOC method for samples with high water vapour content $>0.8$ vol- $\%$ ). 


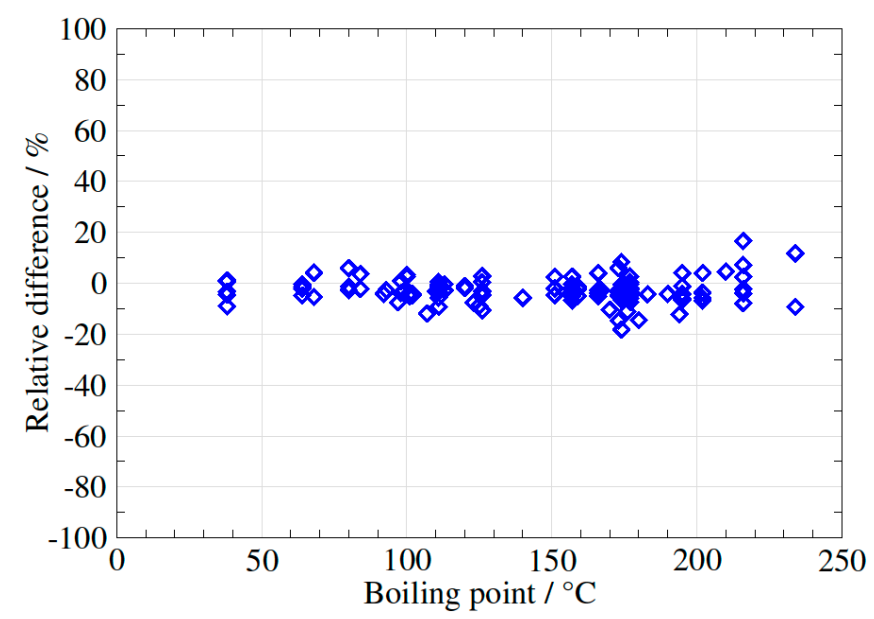

Figure 6. Difference in VOCs concentrations measured with the syringe method versus the EasyVOC method.

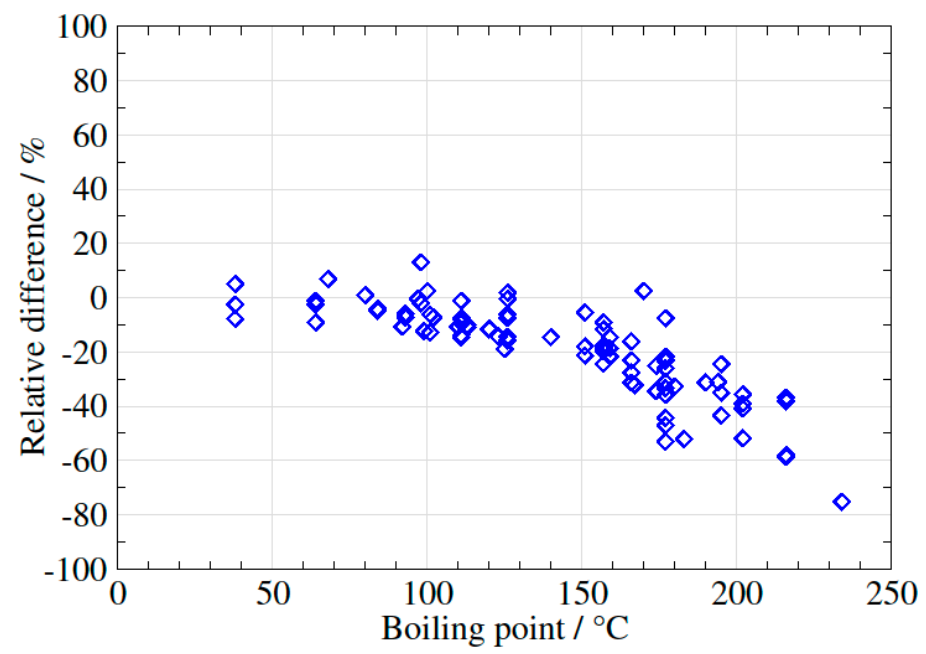

Figure 7. Difference in VOCs concentrations measured with the sampling pump method versus the EasyVOC method (water vapour $<0.8$ vol-\%).

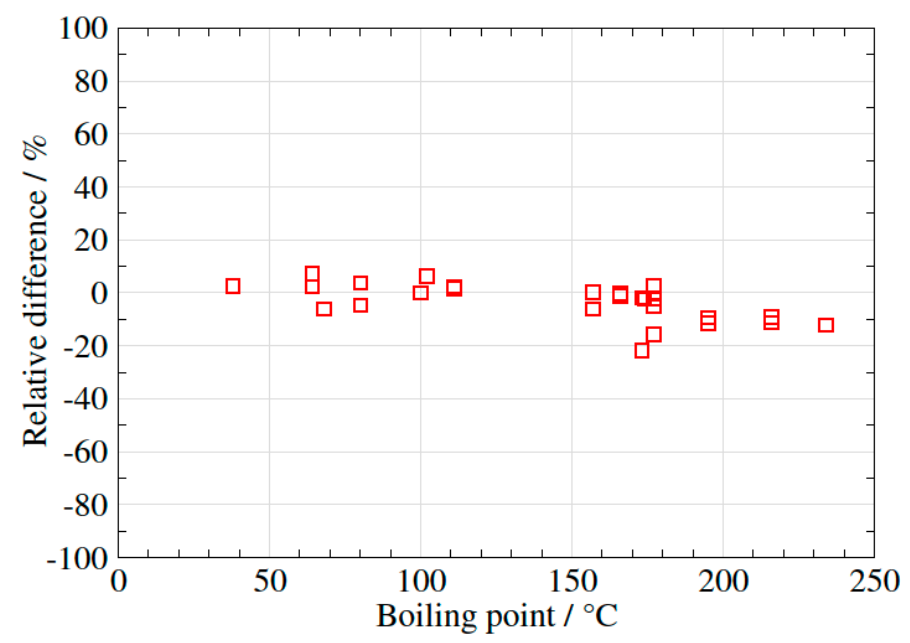

Figure 8. Difference in VOCs concentrations measured with the sampling pump method versus the EasyVOC method (water vapour $>0.8$ vol- $\%$ ). 
The two methods give very comparable results ( 98 values out of 130 in the interval $\pm 5 \%, 22$ values out of 130 in the intervals 5 to $10 \%$ or -5 to $-10 \%$, and only 10 values in the intervals 10 to 20 or -10 to $-20 \%)$.

The two methods give comparable results (Figure 8 ( $\pm 10 \%$ with one outlier), if the samples contain a relatively high level of water vapour.

However, if the samples contain a relatively low level of water vapour, the two methods give comparable results for VOCs with boiling points up to $120^{\circ} \mathrm{C}$ but, for VOCs (Figure 7) with higher boiling points, the sampling pump method (with a flow rate of $50 \mathrm{~mL} / \mathrm{min}$ ) tends to underestimate the concentrations when compared to the two other methods. The influence of humidity on storage of VOCs have been discussed in some studies [25,26]. Two phenomena having opposite effects have been discussed in studies where humid gases are stored. On the one hand, depending on their water solubility, compounds may dissolve in condensed water and, on the other hand, water itself has a tendency to absorb on the vessel's surfaces, thus occupying the actives sites on these surfaces and thereby contributing to the inertness of the vessel.

The most notable difference between the sampling pump method and the other methods is the flow rate, which is much lower for this method. For compounds with high boiling points, some adsorption effects may be responsible for the lower concentrations observed when the flow rate is low. The water molecules probably compete with the targeted compounds for adsorption on the active sites, leading to a better recovery even when sampling at low flow rates.

Methods 1 and 2 have also the advantages that they can be easily be applied onsite, the sampling can be carried out by unskilled personnel and requires only limited equipment while method 3 requires training and the equipment requires either onsite power supply or the use of batteries that must be fully charged before sampling.

Regarding costs, methods 1 and 2 are less inexpensive in terms of both investment and operational costs than method 3 as they only require either a syringe or a grab sampler, while method 3 requires both a sampling pump and a flow meter (higher investment costs and relatively low operational costs).

\section{Conclusions}

Assessing the quality of biogas or biomethane to ensure that the gas can be used technically and safely requires reliable analytical methodologies where sampling is of critical importance. Taking samples in gas bags or on adsorbent tubes are two common methods for sampling biogas and biomethane for determining impurities (present in the gas at ppb-vol level or at max. some few ppm-vol). However, when sampling in gas bags, short-term storage stability may be an issue and, when sampling on to adsorbents, the sampling train requires the flow rate to be stable during the sampling, which may not always be possible onsite. Combining the two methods may provide a solution to overcome the drawbacks associated with each method. In this study, we propose sampling in a gas bag first and then directly transferring the gas onto an adsorbent tube. However, we show here that the transfer must be done at relatively high flow rates, primarily if the gas contains a high amount of water. The recommended flow rate is at least $300 \mathrm{~mL} / \mathrm{min}$ and up to $500 \mathrm{~mL} / \mathrm{min}$. If lower flow rates are used, concentrations may be underestimated and this will especially affect compounds with higher boiling points (higher than $150^{\circ} \mathrm{C}$ ).

Author Contributions: Conceptualization, K.A.; Methodology, K.A. and A.F.; Validation, K.A. and A.F.; Formal Analysis, K.A., A.F., and O.B.; Investigation, K.A., A.F., and O.B.; Resources, K.A., A.F., and O.B.; Data Curation, K.A.; Writing-Original Draft Preparation, K.A.; Writing-Review and Editing, O.B.; Visualization, O.B. and K.A.; Project Administration, K.A.; Funding Acquisition, K.A. and O.B.

Funding: Research funded by VINNOVA (2017-05008)—Swedish Governmental Agency for Innovation Systems.

Conflicts of Interest: The authors declare no conflicts of interest. 


\section{References}

1. House, D. The Complete Biogas Handbook; Alternative House Information; OCLC: Dublin, OH, USA, 2010.

2. Aebiom. A Biogas Road Map for Europe; Annual Report 2009; European Biomass Association: Brussels, Belgium, 2010.

3. Arrhenius, K.; Johansson, U. Characterization of Contaminations in Biogas before and after Upgrading to Vehicle Gas; SGC Report No. 246; SGC: Malmö, Sweden, 2012.

4. EN 16723-1:2016-Natural Gas and Biomethane for Use in Transport and Biomethane for Injection in the Natural Gas Network-Part 1: Specifications for Biomethane for Injection in the Natural Gas Network; DIN: Berlin, Germany, 2016.

5. EN 16723-2:2017-Natural Gas and Biomethane for Use in Transport and Biomethane for Injection in the Natural Gas Network-Part 2: Automotive Fuels Specification; DIN: Berlin, Germany, 2016.

6. Arrhenius, K.; Yaghooby, H.; Rosell, L.; Büker, O.; Culleton, L.; Bartlett, S.; Murugan, A.; Brewer, P.; Li, J.; van der Veen, A.M.H.; et al. Suitability of vessels and adsorbents for the short-term storage of biogas/biomethane for the determination of impurities-siloxanes, sulphur compounds, halogenated hydrocarbons, BTEX. Biomass Bioenergy 2017, 105, 127-135. [CrossRef]

7. Arrhenius, K.; Brown, A.S.; van der Veen, A.M.H. Suitability of different containers for the sampling and storage of biogas and biomethane for the determination of trace-level impurities-A review. Anal. Chim. Acta 2016, 902, 22-32. [CrossRef] [PubMed]

8. Polman, E.A.; Top, H.; Gerritsen, B.; Rekers, A. Development of Existing and New Measurement Technologies for Determination of the Gas Composition; EDGaR project number 100201910, GT15-0029; Energy Delta Gas Research (EDGaR): Groningen, The Netherlands, 2015.

9. Ajhar, A.; Wens, B.; Stollenwerk, K.H.; Spalding, G.; Yuce, S.; Melin, T. Suitability of Tedlar gas sampling bags for siloxane quantification in landfill gas. Talanta 2010, 82, 92-98. [CrossRef] [PubMed]

10. Mariné, S.; Pedrouzo, M.; Marcé, R.M.; Fonseca, I.; Borrull, F. Comparison between sampling and analytical methods in characterization of pollutants in biogas. Talanta 2012, 100, 145-152. [CrossRef] [PubMed]

11. Arnold, M.; Kajolinna, T. Development of on-line measurement techniques for siloxanes and other trace compounds in biogas. Waste Manag. 2010, 30, 1011-1017. [CrossRef] [PubMed]

12. Ghosh, A.; Seeley, S.K.; Nartker, S.R.; Seeley, J.V. Analysis of siloxanes in hydrocarbon mixtures using comprehensive two-dimensional gas chromatography. J. Chromatogr. A 2014, 1360. [CrossRef] [PubMed]

13. Narros, A.; Del Peso, M.I.; Mele, G.; Vinot, M.; Fernandez, E.; Rodriguez, M.E. Determination of siloxanes in landfill gas by adsorption on Tenax tubes and TD-GCMS. In Sardinia 2009, Proceedings of the 12th International Waste Management and Landfill Symposium, S. Margherita di Pula, Cagliari, Italy, 5-9 October 2009; CISA Publisher: Lucca, Italy, 2009.

14. Rasi, S.; Veijanen, A.S.; Rintala, J. Trace compounds of biogas from different biogas production plants. Energy 2007, 32, 1375-1380. [CrossRef]

15. Badjagbo, K.; Héroux, M.; Aleee, M.; Moore, S.; Sauve, S. Quantitative Analysis of volatile methylsiloxanes in waste-to energy landfill biogases using Direct APCI-MS/MS. Environ. Sci. Technol. 2010, 44, 600-605. [CrossRef] [PubMed]

16. Piechota, G.; Iglinski, B.; Buczkowski, R. Development of measurement techniques for determination main and hazardous components in biogas utilized for energy purposes. Energy Convers. Manag. 2013, 68, 219-226. [CrossRef]

17. McGarvey, L.J.; Shorten, C.V. The effects of adsorption on the reusability of Tedlar Air sampling bags. AIHAJ-Am. Ind. Hyg. Assoc. 2000, 61, 375-380. [CrossRef]

18. Rasi, S.; Lehtinen, J.; Rintala, J. Determination of organic silicon compounds in biogas from wastewater treatments plants, landfills, and co-digestion plants. Renew. Energy 2010, 35. [CrossRef]

19. Kim, N.-J.; Chun, S.-K.; Cha, D.K.; Kim, C. Determination of siloxanes by solid-phase adsorption on activated carbon. Bull. Korean Chem. Soc. 2013, 34, 2353-2357. [CrossRef]

20. Raich-Montiu, J.; Ribas-Font, C.; de Arespacochaga, N.; Roig-Torres, E.; Broto-Puig, F.; Crest, M.; Bouchy, L.; Cortina, J.L. Analytical methodology for sampling and analysing eight siloxanes and trimethylsilanol in biogas from different wastewater treatment plants in Europe. Anal. Chim. Acta 2014, 812. [CrossRef] [PubMed] 
21. Lamaa, L.; Ferronato, C.; Fine, L.; Jaber, F.; Chovelon, J.M. Evaluation of adsorbents for volatile methyl siloxanes sampling based on the determination of their breakthrough volume. Talanta 2013, 115, 881-886. [CrossRef] [PubMed]

22. Brown, R.H.; Purnell, C.J. Collection and analysis of trace organic vapour pollutants in ambient atmospheres. The performance of Tenax-GC adsorbent tube. J. Chromatogr. A 1979, 178, 79-90. [CrossRef]

23. MDHS 40(rev) Toluene in-Laboratory Method Using Pumped Porous Polymer Adsorbent Tubes, Thermal Desorption and Gas Chromatography; HIS Inc.: Bootle, UK, 1990.

24. Scanlon, J.T.; Willis, D.E. Calculation of Flame Ionization Detector Relative Response factors using the Effective Carbon Number Concept. J. Chromatogr. Sci. 1995, 23, 333-340. [CrossRef]

25. Ochiai, N.; Tsuji, A.; Nakamura, N.; Daishima, S.; Cardin, D.B. Stabilities of 58 volatile organic compounds in fused-silica-lined and SUMA polished canisters under various humidified conditions. J. Environ. Monit. 2002, 4, 879-889. [CrossRef] [PubMed]

26. Hsieh, C.C.; Horng, S.H.; Liao, P.N. Stability of trace-level volatile organic compounds stored in canisters and Tedlar Bags. Aerosol Air Qual. Res. 2003, 3, 17-28. [CrossRef]

(C) 2019 by the authors. Licensee MDPI, Basel, Switzerland. This article is an open access article distributed under the terms and conditions of the Creative Commons Attribution (CC BY) license (http:/ / creativecommons.org/licenses/by/4.0/). 